\title{
PROGRESSIVE MYOSITIS OSSIFICANS : REPORT OF A CASE
}

\author{
BY \\ GWYN GRIFFITH, M.D., M.R.C.P.E., D.P.H., D.C.H. \\ (From the Children's Department, Caernarvonshire and Anglesey Infirmary, Bangor)
}

This rare disease of the locomotor system occurs during the period of growth, and insidiously but inevitably brings about immobilization. It is characterized by the appearance of bone in muscles, tendons, fasciae, and aponeuroses, and by the occurrence of exacerbations and remissions in the course of the disease, and of congenital bony anomalies.

According to Batten (1910), the earliest case on record was reported by Frieke in 1740, and the same author mentions that a complete account was given by Robert, Bishop of Cork, and the Reverend Dean Copping, in 1741, of a boy who showed the first signs of the disease at eighteen and died at the age of sixty-one.

Koontz (1927) mentions that Patin in 1692 wrote of a woman 'who became as hard as wood all over', that the condition was given its present name by Von Dusch in 1868, and that Munchmeyer wrote the first description in 1869 . He also states that Helferich in 1879 first noted the association with microdactyly. Koontz mentions some theories of causation, viz. retention of calcium, congenital predisposition towards ossification of intramuscular connective tissue, fascia, and aponeurosis, extravasation of blood into tissue, inflammatory process of intermuscular connective tissue, and disturbances of embryonic development.

Rolleston (1901) believes the condition to be a developmental disease of the mesoblast. He mentions similar ideas as to the cause. - It is suggested that in myositis ossificans progressiva the process is a metaplasia of fibrous tissue to cartilage and bone: The disease is, in a sense, misnamed, as the whole pathological process is enacted in and around interstitial connective tissue. In essentials the disease consists of a gradually progressing ossification in this tissue, during the process of which muscle fibres become atrophied and compressed and disappear. In some instances the process may not go so far, for example in calcinosis interstitialis multiplex, where the interstitial connective tissue is the site of deposition of calcium salts. These two closely allied conditions are due to a primary disturbance of development of connective tissue on which is superimposed a disorder of calcium metabolism of unknown origin, permitting in the one case the development of hard, bony masses and in the other of calcium deposits in similar situations.
Koontz (1927) mentions that Rosenstirn reports: three instances in which heredity appeared to be a factor. In one instance the grandfatber, father, and three sons all had microdactyly and a tendency to haemorrhage.

No treatment is known which will alter or arrest the course of the disease, although the coincidence of treatment with a remission has led to reports of apparent cure. For example Frölich (1926), who noted that fractures in diabetics did not heal readily, thought that ketosis might influence the condition favourably. A patient aged two years six months was placed on a ketogenic diet for eighteen months. No more calcareous areas developed and, of the ones already present, some disappeared and others diminished greatly in size. Van Creveld and Soeters (1941) mention several therapeutic agents which have been employed with disappointing results: for example beryllium carbonate (to form an insoluble phosphate in the intestine), ketogenic diet, sodium citrate (on the basis of the good results obtained in calcinosis interstitialis), parathyroid (used without effect in their reported case), vitamins $B_{1}$ and $E$, disodium hydrogen phosphate (favourable results in calcinosis interstitialis), and a low calcium diet. Deep x-ray therapy and surgical removal of bone have produced no beneficial result. Clinical features of the disease are 'accident proneness', a tendency to tissue haemorrhage, with bone dystrophies in 70 per cent. of cases (Uehlinger, 1936), and the occurrence of remissions and exacerbations. The disease tends to be more common in males than in females in the ratio of four to one. It commonly affects the muscles of the back, with fixation of the scapula to the thorax. The neck is fixed and bent to one side. Arm movements are limited or impossible. It gradually affects the masseters and temporals and even the ocular muscles. Certain groups escape, viz. those of facial expression, platysma, tongue, deglutition, larynx, diaphragm, heart, perineum, genital apparatus, and sphincters. The diagnosis is made on a history of injury, followed by bruising and the appearance of muscle masses, in association with skeletal abnormalities in young children.

Mair (1932), in a very full discussion of the disease, mentions that torticollis may be simulated at first, and also rheumatic infection. In infancy cephalhaematoma and sterno-mastoid tumour may. be simulated. He notes that in the early stages the diagnosis must be made from myositis fibrosa, 
which has a similar mode of spread but occurs later in life, attacks the lower limbs first, and is associated with pain; from dermatomyositis, in which involvement of the muscles, skin, and subcutaneous tissues occurs simultaneously and progresses rapidly; from polymyositis haemorrhagica, in which cardiac phenomena are rarely absent and haemorrhage with fever is always present; and from calcinosis interstitialis multiplex ossificans (progressiva et regressiva), in which the lesions are hard, but in a considerable number of cases nodules ulcerate through the skin and discharge their chalky contents. Ryan (1945) has reported, however, a case of myositis ossificans progressiva in which ulceration occurred in the thigh. Congenital abnormalities are generally absent, and in calcinosis interstitialis tendons and fasciae are never attacked. Mair also states that microdactyly is an important but not an infallible help in diagnosis. Mair notes that in the late stages the diagnosis must be made from multiple exostosis, in which there is always a definite point of attachment to the bony skeleton whereas in myositis ossificans progressiva bony masses appear loose in the muscles. The prognosis is grave, and death may be due to intercurrent tuberculosis or pneumonia. If the disease comes on in infancy children seldom live beyond the age of fifteen years.

\section{Case Report}

The patient is a female child aged three years, who, in October, 1947, fell and injured the back of her head. About a week after this she was seen by her doctor, who found a hard, painless, nontender swelling over the occiput. It was an ovoid mass about 1 by $1 \frac{1}{2}$ inches which pitted slightly on pressure. There were no other symptoms or signs and the mass softened, became dispersed, and disappeared altogether in three weeks. She was kept under careful observation during this period and no rise of temperature or pulse rate was noted. The child was seen again three weeks later as her parents had noticed a swelling in her neck. It was said that she had received a very slight knock on the back of her head fourteen days previously, which was followed in a few days by this swelling. On examination a hard mass was noticed on the back of the neck to the right of the mid-line and extending from the base of the skull to the level of the seventh cervical vertebra. She was admitted into hospital at this time, on Nov. 10, 1947.

She was the second of two children and had been born by normal delivery at full term, the birth weight being $6 \mathrm{lb} .7 \mathrm{oz}$. No abnormality was noted at birth. Her mother developed a breast abscess, and the infant was fed on diluted cow's milk with added halibut liver oil and vitamin C. She wás vaccinated in early life and immunized against diphtheria, both without abnormal reactions. Development was normal, with teething commencing at nine months. She sat up unsupported at nine months, and walked at the age of thirteen months. She had whoopingcough at the age of six weeks and ulcerative stomatitis at the age of two years. At ten months she had a fractured cervical spine which was treated by immobilization. It was said that although she walked normally, she appeared to fall easily.

FAMILY HISTORY. Her mother had an uneventful pregnancy and had always been healthy. Her father had always been healthy and there was no history of abnormality on either side. The first child, a normal boy, had died following an operation for acute appendicitis.

Clinical examination. The child was of normal height but appeared pale and fragile and apprehensive. There was a mass on the back of the neck, limited by the mid-line, with some redness of the overlying skin, and a small healed abrasion in the right occipital region. The sclerotics appeared more blue than normal. Muscle tone was poor. The great toes were shorter than normal, apparently consisting of one phalanx only, and associated with hallux valgus. There was similar shortening of the thumbs, and the little fingers of both hands were curved. The central nervous system was normal. No abnormality was found in the cardiovascular system nor in the respiratory system. There was no palpable mass in the abdomen. The only other clinical abnormality detected was a mild patchy glossitis. During her stay in hospital she slipped and sustained a very mild blow on her forehead. A bruise developed rapidly. There was no other evidence of bleeding and Hess' capillary resistance test was negative.

INVESTIGATIONS. Haemoglobin was 76 per cent.; the red cell count $4,300,000$ per c.mm. of blood; the differential count: neutrophils 40 per cent., lymphocytes 55 per cent., monocytes 3 per cent., basophils 1 per cent., eosinophils 1 per cent. The bleeding time was 3 minutes 15 seconds, and the coagulation time 6 minutes 45 seconds. Urine examination showed a very faint cloud of albumin, with numerous pus cells and motile bacilli. A coliform organism was cultured. Estimation of creatine in the urine showed creatine (as creatinine) $4 \mathrm{mg}$. (normal 0 to $15 \mathrm{mg}$.), and preformed creatinine $0.65 \mathrm{mg}$. (normal 0.5 to $1 \mathrm{~g}$.). Calcium balance estimations performed on the low calcium diet suggested by Abrahams and Widdowson (1940) were inconclusive. During her stay in hospital she had pyrexia varying from 99.4 to $100 \cdot 5^{\circ} \mathrm{F}$. which was attributed to the urinary infection and which responded to treatment with sulphathiazole and potassium citrate.

A series of radiographs were taken, with the following findings. The chest showed no abnormality. The hand showed a small and broad first metacarpal and middle phalanx of the little finger, and one phalanx only in the thumb. It also showed the curving of the little finger (fig. 1). The foot showed a hallux valgus deformity, and a short and broad first metatarsal, with a deformity of the distal end of this bone. The femur showed a broad neck (fig. 5). The skull had an irregular bony mass below the occiput (fig. 4). All the radiographs of 


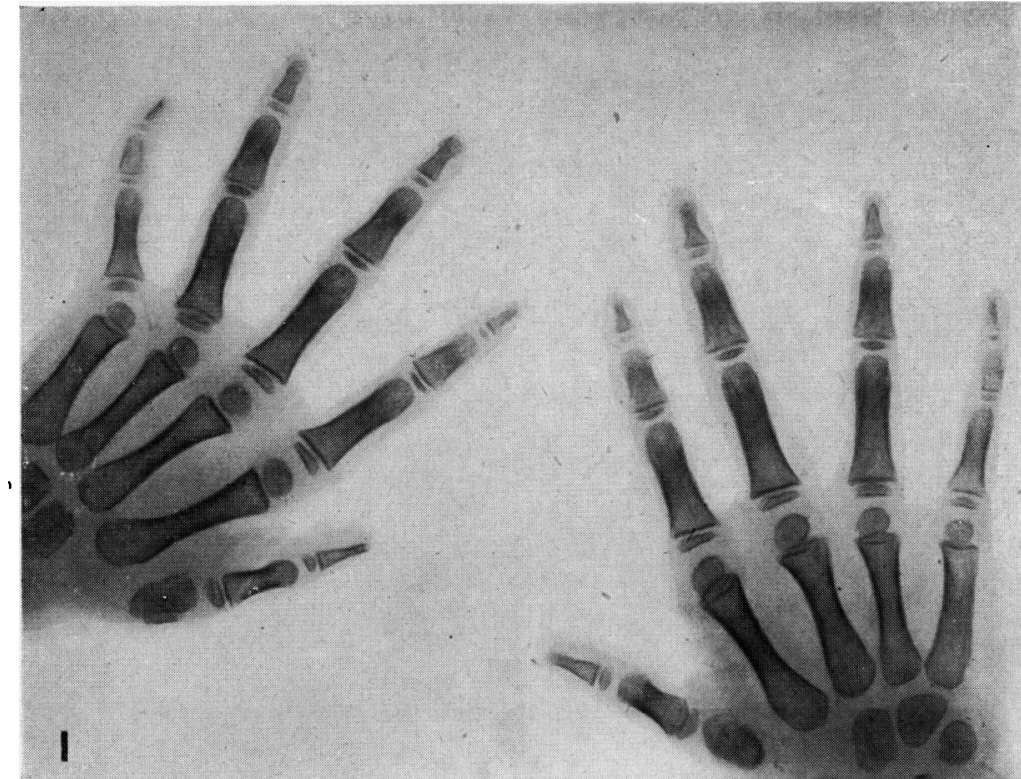

FIG. 1. Radiograph of the hands showing microdactyly of the thumb, apparently due to the absence of one phalanx and a deformed first metacarpal, and terminal incurving of the little finger.

FIg. 2. Photograph showing the child's posture when examined in December, 1947.
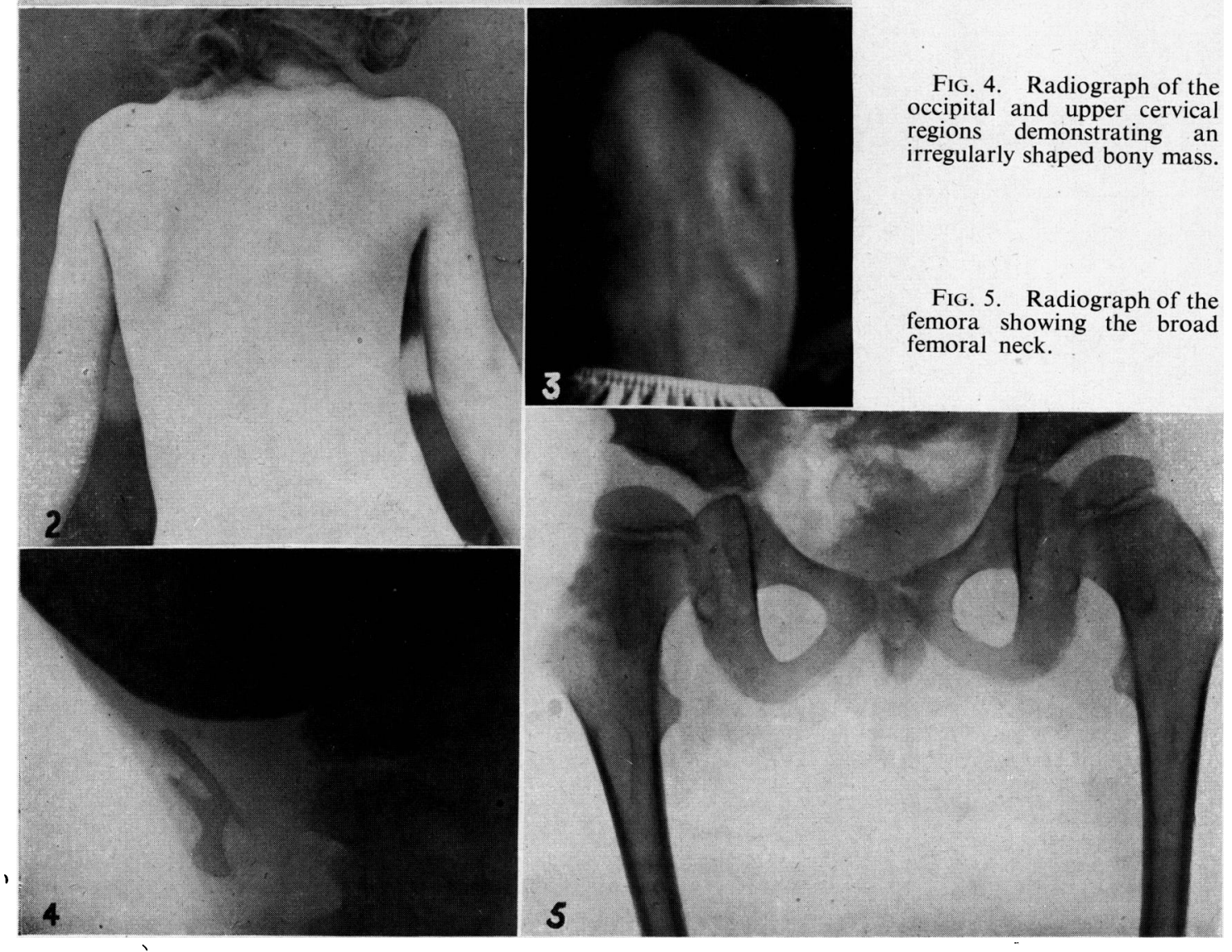

Fig. 3. Photograph showing the child's present posture, demonstrating also the site of three bony masses.

FIG. 4. Radiograph of the ccipital and upper cervical regions demonstrating an irregularly shaped bony mass.

FIG. 5. Radiograph of the femora showing the broad femoral neck. 
the skeleton showed generalized osteoporosis, and also exostosis at the upper end of the right humerus.

TREATMENT. The patient was treated with iron, vitamins, and sodium citrate.

FURTHER PROGRESS. During her stay in hospital the muscle mass which first appeared in the right trapezius became less and in about two weeks had become flattened and indurated. No other muscle involvement occurred at this time. She was discharged from hospital on Nov. 27, 1947.

On Dec. 11, 1947, rigidity of the right trapezius was noted. The muscles of the spine on the right side felt rigid with two prominent masses (fig. 2), and the whole chest wall posteriorly was hard and unyielding on palpation. She was unable to bend her spine. There was a new mass in the latissimus dorsi in the posterior axillary line. Radiographs of the neck showed increasing density of the muscle shadow.

On Jan. 1, 1948, flattening and contraction of the muscle masses was noticed, with increasing induration, and also thickening and induration of the right deltoid muscle. No mass had been previously observed in this muscle.

On Jan. 20, 1948, a mass was noticed in the right biceps with resulting immobilization of the right elbow at a right angle.

By April 7 there was diffuse thickening of the left rectus abdominis and external oblique muscle with marked induration along the centre of the muscle and near its insertion into the pubis. There were also areas of induration in the abdominal wall near the left costal margin and above the right anterior superior iliac spine.

By Aug. 20 there was curvature of the spine (a dorsal kyphosis) with the head fixed, thickening and rigidity of the left sterno-mastoid, and an indurated swelling below the jaw. The range of movement in the previously fixed right elbow was increased, extension being almost complete but flexion being prevented by a rigid and hard right triceps. The whole of the left rectus abdominis was hard and rigid. There was no evidence of disease in the muscles of the lower limbs. There was thickening and hardening of the masseters with increasing difficulty in opening the mouth. She was able to feed herself with encouragement from her parents. Fig. 3 shows the child's present posture.

\section{Comment}

This case shows the common onset in the muscles of the neck with apparent resolution leaving a rigid and considerably smaller mass. Bone which was present in the radiograph (fig. 4) on March 31, 1948, was not shown in a film taken in October, 1947.
Remissions and exacerbations which have been described in this disease are demonstrated, and also the rapid progress and resolution of muscle swellings described by Garrod (1907). The case also shows the association with trauma and the tendency to bruising with almost negligible trauma, although bleeding time was normal and capillary fragility could not be demonstrated. Another feature was the incidence of falls, although it is possible that no comment would have been made on this point except for the consequent bruising. Microdactyly was present in the thumbs and great toes, with hallux valgus deformity in the latter. Radiographs showed bone dystrophies in other bones, viz. the first metatarsal and first metacarpal, the middle phalanx of the little fingers, and apparently the neck of the femur.

Two types of muscle involvement were noticed; one in which there was a dramatic onset of a large mass which resolved over a period of three weeks, and the other in which there was an insidious progress of muscle induration without an apparent antecedent muscle mass. This was noticed particularly in the right triceps and the right deltoid.

In this case the right side of the body had become considerably involved before there was any evidence of the disease on the left side.

\section{Summary}

A case of progressive myositis ossificans is reported in a girl of three years, with notes on theories of etiology, clinical features, and differential diagnosis; and mention is made of the numerous but disappointing varieties of treatment.

My thanks are due to Dr. D. Glanville Evans for his careful notes and to Dr. Gerald Evans and Mr. Goronwy Thomas for helpful criticism.

\section{REFERENCES}

Abrahams, M., and Widdowson, E. M. (1940). Modern Dietary Treatment. London. Second edit., p. 119.

Batten, F. E. (1910). In Allbutt, C., and Rolleston's, H. D., System of Medicine, vol.vii,p. 11. London.

Frölich, T. (1926). Acta Paediatr., 5, 294 (abstract in Amer. J. Dis. Childh., 32, 145).

Garrod, A. E. (1907). St. Barts. Hosp. Rep., 42, 43.

Koontz, A. K. (1927). Amer. J. med. Sci., 174, 406.

Mair, W. F. (1932). Edinb. med. J., 39, 69.

Rolleston, H. D. (1901). Clin. J., London, 17, 209.

Ryan, K. J. (1945). J. Pediat., 27, 348.

Uehjinger, E. (1936). Quoted by Caffey, J. Pediatric X-ray Diagnosis. Chicago. 1945. p. 551. Year Book Publishers. First edit.

Van Creveld, S., and Soeters, J. M. (1941). Amer. .I Dis. Child., 62, 100 n. 